\title{
III PREMIO
}

«TEORÍA Y REALIDAD CONSTITUCIONAL» PARA JÓVENES CONSTITUCIONALISTAS 

En el número 25 de nuestra revista se hicieron públicas las Bases de éste II Premio para artículos científicos de jóvenes constitucionalistas, al que se presentaron dieciocho trabajos inéditos y sólo firmados con seudónimo (con el nombre del autor en plica cerrada).

Constituido el Jurado por los profesores de la disciplina: Dr. D. ÓsCar Alzaga VILLAAMIL (Catedrático de Derecho Constitucional de la UNED y Director de la Revista Teoría y Realidad Constitucional) quien actúa como Presidente, Dr. D. LuIs AGUIAR DE LuQUE (Catedrático de Derecho Constitucional de la Universidad Carlos III), Dra. D ${ }^{a}$ PIEDAd García-Escudero Márquez (Catedrática de Derecho Constitucional de la Universidad Complutense de Madrid), Dr. D. Antonio López Pina (Catedrático de Derecho Constitucional de la Universidad Complutense de Madrid), Dr. D. Pablo Santolaya Machetti (Catedrático de Derecho Constitucional de la Universidad de Alcalá de Henares), Dr. D. JuAn José SolozÁBAl Echavarría (Catedrático de Derecho Constitucional de la Universidad Autónoma de Madrid) y Dr. D. José MAnuel Vera SAntos (Catedrático de Derecho Constitucional de la Universidad Rey Juan Carlos) — como Secretario con voz pero sin voto- el Dr. D. Fernando Reviriego Picón (Profesor Titular de Derecho Constitucional de la UNED y Secretario de Teoría y Realidad Constitucional), se produjo la deliberación y la votación subsiguiente.

Mediante votación secreta y por unanimidad se acordó otorgar ex aequo el primer premio a los siguientes trabajos:

— «La forja jurisprudencial del principio de transparencia. Análisis del derecho de acceso público a documentos y sus excepciones en la jurisprudencia reciente del Tribunal de Justicia de la Unión Europea», cuya autora, abierto el sobre de la plica es Da Blanca Ballester Martínez.

— «Teoría contra-mayoritaria: Consideraciones de la countermajoritarian difficulty», cuyo autor, abierto el sobre de la plica es D. Mauro Arturo Rivera León.

Conforme a lo establecido en las Bases, amén de retribuir económicamente a los autores premiados, Teoría y Realidad Constitucional se honra en publicar a continuación ambos trabajos y transmitir a aquellos la felicitación más sincera de nuestro Consejo de Redacción.

Junto a ello la Comisión ha acordado otorgar sendos accésit a los trabajos:

- « ¿Admisión discrecional de los recursos de amparo por el Tribunal Constitucional? Balance de tres años de aplicación del nuevo trámite de admisión, cuyo autor, abierto el sobre de la plica es D. Mario Hernández Ramos.

— «El retraso en la designación parlamentaria de magistrados constitucionales», cuyo autor, abierto el sobre de la plica es D. José ANTONIO EstradA MARÚN.

En Madrid, a 4 de mayo de 2011 



\title{
LA FORJA JURISPRUDENCIAL DEL PRINCIPIO DE TRANSPARENCIA
}

\author{
BLANCA BALLESTER MARTÍNEZ* \\ Administradora del Parlamento Europeo
}

SUMARIO.-

I. Introducción.

II. Marco jurídico: el Reglamento 1049/2001 del Parlamento Europeo y del Consejo relativo al acceso del público a documentos del Parlamento Europeo, del Consejo y de la Comisión.

III. Marco jurisprudencial: la jurisprudencia del Tribunal de Justicia de la Unión Europea sobre acceso público a los documentos de las instituciones.

IV. Bavarian Lager: una reinterpretación de las excepciones.

V. Conclusiones.

\section{INTRODUCCIÓN}

El principio de transparencia tuvo su origen en los países escandinavos, cuyo compromiso con la apertura de sus gobiernos y administraciones data de mediados del siglo XVIII. Con la inminente entrada a la UE de dos nuevos miembros escandinavos en 1995 (Suecia y Finlandia), y siguiendo la hasta entonces débil corriente auspiciada por Dinamarca, el principio de transparencia penetró en la administración comunitaria a principios de los años 90. Ya por entonces se intuían las dos maneras ${ }^{1}$ en las que iba a mate-

* Dedicado a mi padre.

Agradezco a Fergal Ó Regan, Jefe de Unidad en el Defensor del Pueblo Europeo, su inspiración y su buen juicio jurídico, que me fueron de gran ayuda para la redacción de este artículo.

1 La doctrina reconoce hasta cuatro manifestaciones del principio de transparencia en la Unión Europea: DYRBERG habla de: i) Procesos decisorios aplicados en las instituciones; ii) Presentación y redacción de los textos de la Unión; iii) Política de información; iv) Acceso público a los documentos que obran en poder de las autoridades públicas. Ver DYRBERG, P.: «El acceso a los documentos y a las autoridades comunitarias», en $R e-$ vista de Derecho Comunitario, 1997-2; págs. 377-379. 
rializarse dicho principio: por un lado, la profundización y el control democráticos en las instituciones; por otro, la apertura de sus procedimientos. Como escribe Guichot, «el reconocimiento del derecho de acceso a documentos en el Derecho europeo se ha vinculado con el principio de democracia, y sus exigencias de participación y control de los ciudadanos en los asuntos públicos, de transparencia ${ }^{2} »$.

La transparencia, entendida en este segundo sentido, es esencial e inevitable en toda democracia, dado que proporciona a los ciudadanos ${ }^{3}$ un instrumento, la información, gracias al cual pueden ejercer un control constante sobre el proceso político y sobre la administración pública. En efecto, el Tratado de Maastricht supuso el germen del principio de transparencia en el acervo comunitario al afirmar que las decisiones a escala europea deberían tomarse lo más cercana y abiertamente posible de cara al ciudadano ${ }^{4}$. El Consejo, la Comisión y el Parlamento firmaron muy pronto un acuerdo interinstitucional (de 25 de octubre de $1993^{5}$ ) del cual nació el Código de Conducta de 6 de diciembre del mismo año ${ }^{6}$, documento que consagraba en la práctica el acceso a los documentos de las instituciones europeas ${ }^{7}$. El artículo 255 del TCE ${ }^{8}$, añadido por la reforma de Ámsterdam,

2 GUICHOT, E. «El nuevo Derecho europeo de acceso a la información pública» en Revista de Administración Pública, no 160. Enero-abril 2003, pág. 296.

3 Es necesario puntualizar, antes de que pueda llevar a confusión, que no debe confundirse el derecho de acceso público a los documentos, del cual tratan estas páginas, con el derecho que toda parte en un procedimiento administrativa tiene a conocer las resoluciones que le afectan y los documentos en los que éstas se fundan. En el primer caso, no es necesario ser parte en ningún procedimiento o negociación para tener acceso a los mismos.

4 Actualmente se recoge en el artículo 15 del TUE modificado por el Tratado de Lisboa, como veremos más abajo.

5 Acuerdo interinstitucional «Legislar mejor»(2003/C 321/01), C, DOUE de 31 de diciembre de 2003.

6 Decisión 93/731/CE, de 6 de diciembre.

7 En puridad no podemos dejar de observar que gran parte del empuje a la transparencia a escala europea se debe a las iniciativas patrocinadas por el Consejo de Europa desde hace décadas. Debemos citar como texto pionero la Recomendación de la Asamblea General 854 (1979) relativa al acceso del público a los documentos oficiales y a la libertad de información, que, en palabras de GUICHOT, inspirada en la Freedom of Information Act estadounidense, sugiere a los Estados miembros del Consejo de Europa un sistema de libre acceso a los documentos oficiales sometido a una serie de excepciones. Dos años más tarde el Comité de Ministros aprobó el texto de referencia, la Recomendación 19 (1981) de 25 de noviembre, sobre el acceso a la información en poder de las autoridades públicas, que apuntaba un mínimo estándar común para todos los Estados miembros. El principio general que establecieron fue el derecho de acceso a la información en poder de la Administración, pero no del resto de los poderes del Estado. El sujeto activo de dicho derecho sería toda persona, sin que cupiese exigir un interés particular en la información en cuestión, si bien se permiten excepciones por motivos de orden público o privado. De hecho, es conveniente señalar que el Tribunal Europeo de los Derechos Humanos ha abordado también el tema de la transparencia y del acceso de los documentos en poder de la administración en sentencias como las recaídas en los asuntos Leander (26 de marzo de 1987), Gaskin (7 de julio de 1989) o Guerra y otros (19 de febrero de 1998). Ver GUICHOT, op. cit. pág. 285.

$8 \mathrm{El}$ artículo 255 del TCE introducido por el Tratado de Ámsterdam rezaba como sigue: «1. Todo ciudadano de la Unión, así como toda persona física o jurídica que resida o tenga su domicilio social en un Estado miembro, tendrá derecho a acceder a los documentos del Parlamento Europeo, del Consejo y de la Comisión, con arreglo a los principios y las condiciones que se establecerán de conformidad con los apartados 2 y 3. 2. El Consejo, con arreglo al procedimiento previsto en el artículo 251, determinará los principios generales y los límites, por motivos de interés público o privado, que regulan el ejercicio de este derecho de acceso a los documentos, en el plazo de dos años a partir de la entrada en vigor del Tratado de Amsterdam. 3. Cada una de las instituciones mencionadas elaborará en su reglamento interno disposiciones específicas sobre el acceso a sus documentos.» 
supuso la positivización del principio general del derecho de acceso a documentos, el cual se consagró en el Reglamento 1049/2001 de 31 de mayo del Parlamento Europeo y del Consejo. Sin embargo, los esfuerzos de la Unión por promover la transparencia no se limitaron a dicho Reglamento, como veremos más abajo cuando analicemos en mayor detalle el recorrido legislativo del principio, y después derecho, de acceso público a los documentos. Hoy por hoy es un derecho fundamental en la Unión Europea, pero esto no significa que sea un derecho absoluto. Existen otros derechos que chocan directamente con el ejercicio del que nos ocupa, como puede ser el derecho a la intimidad o la protección de datos personales 9 , y en ciertos casos es necesario reconciliarlos entre ellos. Además, el equilibrio requiere que se tengan también en cuenta ciertos intereses (como, por ejemplo, las investigaciones de la Comisión Europea) que pueden inclinar la balanza a favor de la confidencialidad en ciertos casos. Es en estas tesituras en las que el Tribunal de Justicia de la Unión Europea, en cada una de sus dos instancias, juega un papel esencial como árbitro y juez, interpretando convenientemente y aplicando la normativa al respecto.

Como podremos observar a lo largo de estas líneas, la labor creativa y creadora del Tribunal de Justicia de la Unión Europea en sede del principio de transparencia y del derecho de acceso público a documentos es tal que casi podemos hablar de actos de legislación por parte del Juez europeo. Adelantándose a las normas que habrían después de seguir sus pasos, el Tribunal de Justicia ha obligado a las instituciones a abrir sus archivos, ha interpretado restrictivamente las excepciones a la apertura y ha reprobado las actitudes oscuras y evasivas de las instituciones cuyos documentos requerían los ciudadanos. Sin embargo, parece que en los últimos casos el Tribunal de Justicia ha iniciado una nueva línea de interpretación de dichas excepciones que, en la práctica, puede llevar a una ampliación de facto de las excepciones que, como veremos, se recogen en el artículo 4 del Reglamento 1049/2001. En otras palabras, asistimos hoy a la configuración del principio de transparencia del futuro, aupado a la categoría de derecho fundamental por el Tratado de Lisboa, y, sin embargo, las sentencias más recientes lo dibujan ligeramente más limitado de lo que solían.

El objetivo de este artículo será precisamente la investigación de una de las más recientes líneas jurisprudenciales al respecto, con el fin último de determinar cómo el Tribunal de Justicia de la Unión Europea va perfilando la compatibilidad del derecho fundamental a la transparencia con otros derechos fundamentales, como son la intimidad y la integridad personal. Para ello comenzaremos por abordar la legislación existente en materia de acceso a documentos, procediendo después al análisis de la jurisprudencia centrándonos en la reciente sentencia del asunto Bavarian Lager. Al final de estas líneas pretendemos extraer conclusiones al respecto y determinar si estamos ante un giro jurisprudencial y, en ese caso, cuáles pueden ser los motivos que empujan al Tribunal de Justicia de la Unión Europea a fallar en un sentido o en otro cuando la transparencia choca con otros bienes jurídicos. Pero, antes de introducirnos de lleno en el estudio de la jurisprudencia, deberemos analizar el marco jurídico que sostiene el derecho de acceso a documentos en la Unión Europea.

9 Artículos 7 y 8 de la Carta de Derechos Fundamentales de la Unión Europea, que reproduciremos en la nota 69 


\section{MARCO JURÍDICO. EL REGLAMENTO 1049/2001 DEL PARLAMENTO EUROPEO Y DEL CONSEJO RELATIVO AL ACCESO DEL PÚBLICO A DOCUMENTOS DEL PARLAMENTO EUROPEO, DEL CONSEJO Y DE LA COMISIÓN}

Las primeras normas comunitarias acerca del acceso a documentos se remontan a $1983^{10}$ y son normas puramente internas que se limitan en su ámbito de aplicación a la Comisión y al Consejo. Hasta la Conferencia Intergubernamental que culminó con la revisión de los Tratados en Maastricht no volvió a haber intento alguno de avance en este tema $^{11}$ y ${ }^{12}$. La Declaración no 17 anexa al Tratado de la Unión Europea trató la cuestión, señalándose que «la transparencia del proceso de decisión refuerza el carácter democrático de las instituciones, así como la confianza del público en la administración» y recomendándosele a la Comisión que «presente al Consejo, a más tardar en 1993, un informe sobre las medidas destinadas a mejorar el acceso del público a la información de que disponen las instituciones ${ }^{13}$ ». Ambos mandatos se hicieron oportunamente realidad en el año previsto debido a las complicaciones que sufrió el proceso de ratificación, agudizándose la necesidad de transparencia en los Consejos Europeos de Birmingham y de Edimburgo ${ }^{14}$ : posteriormente, en 1993 la Comisión presentó algunas comunicaciones al respecto ${ }^{15}$.

10 Reglamento del Consejo (CEE/CEEA) 354/83, DOCE L 43. De 15 de febrero de 1983. Igualmente, Decisión de la Comisión 359/83/CECA, de la misma fecha. El artículo 1 de ambas reza que «las instituciones crearán archivos históricos y los abrirán al público». Antes existía el Reglamento del Consejo de 1 febrero de 1980 referido al acceso público a los documentos con más de treinta años de antigüedad que obraban en su poder (archivos históricos). Para una explicación más detallada al respecto, ver FORREST, A. «Naissance des archives historiques des Communautés Européennes» en Revue de Marché Commun, 1983, págs. 466-473.

11 En efecto, en dicha CIG Holanda presentó una propuesta que no prosperó, de modo que se excluyó la posibilidad de que se incluyese en el TCE una referencia a la apertura y al acceso a documentos y a su regulación a través de un reglamento. Ver, para un relato más detallado de los hechos, CLOOS, J.; REINESCH, G.; VIGNES, D. y WEYLAND, J.: Le Traité de Maastricht: Genèse, analyse et commentaire. Bruylant, Bruselas, 1994, págs. 418-421.

12 Sin embargo, es reseñable el hecho de que el Tratado de Maastricht creara la ciudadanía europea y la institución del Defensor del Pueblo Europeo, los cuales están íntimamente relacionados con la promoción de la transparencia.

13 Declaración relativa al derecho de acceso a la información, DOCE C191 de 29 de julio de 1992, pág. 101.

14 Ambos Consejos coincidieron en la necesidad de acentuar la transparencia en la Comunidad, instando a la Comisión a que acelere los trabajos sobre el tema. Aparece claramente en las Conclusiones del Consejo Europeo de Birmingham «Una Comunidad cercana a sus ciudadanos», octubre de 1992, Boletín CE 10-1992 pág. 9.

15 El acceso de los ciudadanos a los documentos de las instituciones, DOCE C 156 de 8 de junio de 1993, y Transparencia en la Comunidad, DOCE C 166 de 17 de junio de 1993. Como señala SOBRIDO PRIETO, «la primera de ellas contienen los resultados de un estudio sobre el acceso de los ciudadanos a los documentos en los distintos Estados miembros y en algunos terceros Estados, llegando a la conclusión de que resultaría conveniente permitir un mayor acceso a los documentos en el nivel comunitario; la Comisión se compromete en esta comunicación a adoptar nuevas medidas que hagan posible este principio e insta a las demás instituciones a que procedan de igual modo, proponiendo al respecto la celebración de un acuerdo interinstitutcional en el que se definan «una serie de normas elementales y de requisitos mínimos». La Comisión sugiere una serie de principios (Nuevas medidas, pág. 6) que desarrolla en la segunda comunicación» (SOBRIDO PRIETO, M. «El acceso público a los documentos internos de la Comisión (Comentario a la sentencia del TPI del 5 de marzo de 1997 WWF UK/Comisión, T-105/95)» en Anuario da Facultade de Direito, No 2, 1998, pág. 725). 
En diciembre de $1993^{16}$ se alcanzó el deseado acuerdo interinstitucional, denominado Código de conducta relativo al acceso del público a los documentos del Consejo y de la Comisión ${ }^{17}$. En el mismo se entendía como documento «todo escrito, sea cual sea su soporte, que contenga datos existentes y que esté en poder del Consejo o de la Comisión» y se excluían aquéllos cuyo autor fuera «una persona, organismo o institución ajenos al Consejo o a la Comisión». Además, el principio general que lo regía era que el público tendría «el mayor acceso posible a los documentos», fijándose en función de este principio tanto el procedimiento de solicitud ${ }^{18}$ como la tramitación del acceso. Respecto de éste último, se preveía, además de la forma en la que ha de llevarse a cabo ${ }^{19}$, los supuestos en los que cabía denegar el acceso; esto es, las excepciones. Éstas se referían a supuestos que, como veremos, también contiene la normativa vigente a día de hoy, como la protección del interés público, la intimidad del individuo o el secreto comercial. Es, por tanto, patente que el principio (entonces todavía no derecho) de acceso a documentos nació ya limitado, concediéndose a las instituciones los instrumentos necesarios para coartar, si necesario fuere, la transparencia de sus procedimientos, y erigiendo tanto al Defensor del Pueblo Europeo como al Juez comunitario como garantes del equilibrio.

Al Código de Conducta le siguieron sendas Decisiones relativas al acceso del público a los documentos, respectivamente, del Consejo y de la Comisión: las Decisiones 93/731 y 94/90 20 . Integrando ésta última con el Código de Conducta apareció la Comunicación de la Comisión sobre mejora del acceso a los documentos ${ }^{21}$ (Comunicación 94/C67/03). Sin embargo, a falta de consagración del derecho de acceso público en el Tratado de Maastricht, dichos textos, así como otros similares, se fueron aprobando con la base jurídica del artículo 151.3 TCE, que establecía la competencia de cada uno de los órganos de las Comunidades de entonces. En otras palabras, el tratamiento que se hacía del acceso público a documentos era puramente procedimental, integrado en la normativa administrativa interna de cada institución. No obstante, en palabras de Guichot, resultaba evidente que

16 También en ese mes se publicó el Reglamento interno del Consejo, cuyos artículos 5.1 y 22 entraban en conflicto al tratar la transparencia. Véase el DOCE L 304, de 10 de diciembre, pág. 1.

17 DOCE L 340 de 31 de diciembre de 1993, pág. 41.

18 Ya entonces se establecía el sistema «doble» de solicitud preliminar y solicitud confirmatoria que veremos posteriormente, así como el sistema de recursos alternativos entre el Defensor del Pueblo Europeo o el Tribunal de Primera Instancia (hoy Tribunal General).

19 La consulta de documentos podía ser o bien presencial o bien mediante la entrega de una copia por la cual el solicitante pagaría una tasa razonable. Se le concedía a la institución, en cada caso, la posibilidad de prohibir la utilización del documento con fines comerciales. Otros supuestos que también se incluían hacían referencia a la repetición de solicitudes, a los expedientes voluminosos y otros supuestos problemáticos para los que se concedía a la institución la libertad de encontrar una «solución adecuada» a los mismos

20 Decisión del Consejo 90/731/CE de 10 de diciembre de 1993, DOCE L 340 de 31 de diciembre de 1993, pág. 43, y Decisión de la Comisión 94/90, de 8 de febrero de 1994. DPCE L 46 de 18 de febrero de 1994 , pág. 58.

21 DOCE C 67 de 4 de marzo de 1994, pág.5. El texto incluye algunas novedades como clarificaciones de las excepciones, el examen de las solicitudes, la confidencialidad y el compromismo de proporcionar más información al público acerca de la legislación en materia de confidencialidad y acceso a documentos por medio de una guía, que fue elaborada en 1994. 
el contenido de dichas normas trascendía con mucho lo meramente organizativo, consagrando un auténtico derecho subjetivo de los ciudadanos ${ }^{22}$.

La entrada en vigor del Tratado de Ámsterdam dio un importantísimo empuje a la legislación en materia de acceso a documentos, ya que el artículo 191 A del mismo, introducido en el TCE en el $255^{23}$, «constitucionalizaba el derecho de acceder a los documentos de las Instituciones de la Comunidad» ${ }^{24}$ y permitía por primera vez hablar de derecho y no solamente de principio de Derecho comunitario. Es en este contexto donde se fraguó la normativa actual de acceso a documentos, contenida en su totalidad en el Reglamento 1049/2001 del Parlamento Europeo y del Consejo. Antes de entrar a analizar en detalle el Reglamento, recalquemos, como Guichot, que «a la construcción [del trenzado normativo en torno al derecho de acceso público] se ha llegado de abajo arriba: inicialmente, fueron normas organizativas las que precedieron al reconocimiento constitucional del derecho; en la actualidad, es a partir de dicho reconocimiento constitucional que se ha procedido a modificar las respectivas normas organizativas ${ }^{25}$.

El texto del Reglamento 1049/200126 (que entró en vigor el 3 de diciembre de 2001) se basa en una propuesta de la Comisión presentada el 26 de enero de 2000 que bebía directamente de los códigos de conducta de 1993, pero añadía las resoluciones del Defensor del Pueblo Europeo y la jurisprudencia emanada del Tribunal de Justicia de la Unión Europea, así como aportaciones de la doctrina y sugerencias de los Estados miembros. Posteriormente, tras el «no» francés y holandés a la malograda Constitución Europea en 2005, la Comisión Europea, convencida de que el rechazo se debía en una parte muy importante al desconocimiento que los ciudadanos tenían de la Unión y de lo lejana que parecía para el europeo de a pie, lanzó la Iniciativa de Transparencia Europea. Dicha iniciativa tiene como objetivo la promoción de la transparencia en los procesos de lobbying y de consultas a los interesados, la publicación de cada vez más información acerca del uso de fondos europeos y el desarrollo de normas éticas y estándares de apertura para los funcionarios europeos. Dentro de la misma hay también una parte dedicada a la revisión de las normas de acceso a documentos ${ }^{27}$.

22 GUICHOT, E. «El nuevo Derecho europeo de acceso a la información pública» en Revista de Administración Pública, $\mathrm{n}^{\circ}$ 160. Enero-abril 2003, pág. 293.

23 Dicho artículo consagró el derecho de todo ciudadano o residente en la Unión a acceder a los documentos del Parlamento, del Consejo y de la Comisión, dentro de los principios y límites que debía fijar el Consejo en un plazo de dos años desde su entrada en vigor (es decir, hasta el 1 de mayo de 2001), siguiendo luego la modificación de los Reglamentos internos de cada institución.

24 VV.AA.: El Tratado de Ámsterdam. Análisis y comentarios. Dirigido por M. OREJA AGUIRRE, 1998, vol. 1, pág. 212.

25 GUICHOT, op. cit. pág. 296.

26 Reglamento (CE) nº 1049/2001 del Parlamento Europeo y del Consejo relativo al acceso del público a los documentos del Parlamento Europeo, del Consejo y de la Comisión, DO L 145 de 31 de mayo de 2001, pág. 43. El Reglamento 1049/2001 pasó a ser aplicable el 3 de diciembre de 2001 y sustituye desde entonces a las normas de acceso que habían introducido anteriormente las tres instituciones, es decir, la Decisión 93/731 del Consejo, la Decisión 94/90 de la Comisión y la Decisión 97/632 del Parlamento Europeo.

27 Propuesta de reglamento del Parlamento Europeo y el Consejo, de 30 de abril de 2008, relativo al acceso del público a los documentos del Parlamento Europeo, del Consejo y de la Comisión [COM(2008) 229 final —no publicado en el Diario Oficial]. 
Finalmente, el marco legal de la transparencia en la Unión Europea ha sufrido dos cambios esenciales con la entrada en vigor del Tratado de Lisboa. El primero es la obligatoriedad jurídica de la que a partir del 1 de diciembre de 2009 goza la Carta de los Derechos Fundamentales de la Unión Europea ${ }^{28}$ y 29 , cuyo artículo 41 consagra el derecho fundamental a una buena administración, mientras que el $42^{30}$ recoge el derecho funda-

Con esta propuesta se quiere modificar el Reglamento (CE) nº 1049/2001 con motivo de la moción del Parlamento Europeo, de 4 de abril de 2006, para una resolución sobre el acceso a los textos de las instituciones (A60052/2006), el Reglamento (CE) no 1367/2006, de 6 de septiembre de 2006, sobre el Convenio de Aarhus, y la consulta pública sobre la revisión del Reglamento (CE) nº 1049/2001 (SEC(2008) 29/2). Según la propuesta de Reglamento, se van a modificar los siguientes extremos: —el objetivo del Reglamento, que es garantizar el acceso público a los documentos de las instituciones; - los beneficiarios del Reglamento, que pueden ser cualquier persona física o jurídica, independientemente de su nacionalidad o del Estado donde resida; —el ámbito de aplicación del Reglamento, que excluye los documentos presentados ante los Tribunales por terceros. El ámbito de aplicación también excluye los documentos relacionados con investigaciones que sigan abiertas o sobre las que no se haya adoptado una decisión definitiva; - la definición de «documento», que indica que el documento ha sido oficialmente transmitido a su destinatario o destinatarios, ha circulado dentro de las instituciones o ha sido registrado por cualquier otro medio. La definición de «documento» también se aplica a la información contenida en sistemas electrónicos, siempre que esta se pueda extraer en un formato legible; - las excepciones al Reglamento, que incluyen documentos que afectan a la protección medioambiental, hacen referencia a procedimientos judiciales, de arbitraje y resolución de litigios, y tienen como objetivo proteger los procesos de selección de personal y a las partes contratantes. La divulgación de información personal, ajena a la actividad profesional, de los funcionarios y los grupos de interés se encuentra regulada por la legislación comunitaria sobre el tratamiento de datos personales (Reglamento (CE) $\mathrm{n}^{\circ}$ 45/2001); - las consultas a terceros, que prevén la obligación de consultar a las autoridades del Estado miembro donde se elaboraron los documentos, salvo que estos formen parte de un procedimiento conducente a un acto legislativo o no legislativo de aplicación general; - las solicitudes de documentos, que toman en consideración la claridad con la que se pide el documento, y, en consecuencia, su identificación. Con respecto a las solicitudes confirmatorias, el plazo de tiempo para tramitarlas se amplía de 15 a 30 días laborables. En caso de denegación, incluso parcial, el solicitante puede demandar a la institución ante el Tribunal de Primera Instancia y/o presentar una queja ante el Defensor del Pueblo Europeo; _- el acceso al documento tras la solicitud, que no puede desviarse de las modalidades específicas establecidas en la legislación europea o nacional, concretamente en los casos en que el acceso está sujeto al pago de una tasa; - la divulgación activa de documentos, que proporciona acceso directo a los documentos que forman parte de un procedimiento conducente a un acto legislativo o no legislativo de aplicación general. Cada institución debe definir el resto de las categorías a las que debe tener acceso directo el público.

http://europa.eu/legislation summaries/institutional affairs/decisionmaking_process/114546 es.htm

Sin embargo, a día de hoy la propuesta se encuentra «atascada» en el Parlamento Europeo, y debido a las reticencias y desavenencias de las instituciones no parece que deba esperarse un acuerdo próximo al respecto.

28 La Carta fue proclamada en diciembre de 2000 una primera vez, y luego firmada y proclamada de nuevo el 12 de diciembre de 2007, día anterior a la firma del Tratado de Lisboa (13 de diciembre de 2007. Dicho Tratado concede a la carta el mismo valor legal que los Tratados.

29 En efecto, los artículos 6.1 y 6.3 del actual TUE dicen lo siguiente: «1. La Unión reconoce los derechos, libertades y principios enunciados en la Carta de los Derechos Fundamentales de la Unión Europea de 7 de diciembre de 2000, tal como fue adaptada el 12 de diciembre de 2007 en Estrasburgo, la cual tendrá el mismo valor jurídico que los Tratados. Las disposiciones de la Carta no ampliarán en modo alguno las competencias de la Unión tal como se definen en los Tratados. Los derechos, libertades y principios enunciados en la Carta se interpretarán con arreglo a las disposiciones generales del título VII de la Carta por las que se rige su interpretación y aplicación y teniendo debidamente en cuenta las explicaciones a que se hace referencia en la Carta, que indican las fuentes de dichas disposiciones. (...)

3. Los derechos fundamentales que garantiza el Convenio Europeo para la Protección de los Derechos Humanos y de las Libertades Fundamentales y los que son fruto de las tradiciones constitucionales comunes a los Estados miembros formarán parte del Derecho de la Unión como principios generales».

30 El artículo 42 de la Carta de los Derechos Fundamentales de la Unión Europea dice así: «Todo ciudadano de la Unión o toda persona física o jurídica que resida o tenga su domicilio social en un Estado miembro tiene derecho a acceder a los documentos del Parlamento Europeo, del Consejo y de la Comisión.» 
mental del acceso público a los documentos. Además, el artículo $15^{31}$ del Tratado de Funcionamiento de la Unión Europea (TFUE) extiende legislativamente el derecho de acceso a documentos, aplicándose desde diciembre de 2009 a todas las instituciones de la Unión $^{32}$, así como a los órganos, oficinas y agencias, incluyendo el Consejo Europeo.

Entrando ya en el contenido del Reglamento 1049/2001, debemos indicar antes que nada que tiene por objeto la fijación de los principios, condiciones y límites del derecho de acceso a los documentos del Parlamento Europeo, la Comisión y el Consejo y la creación de mecanismos que faciliten el ejercicio de dicho derecho, así como la promoción de buenas prácticas administrativas que fomenten el ejercicio del mismo ${ }^{33}$. Sin embargo, se asume que el Reglamento sólo cubre el acceso a los documentos administrativos que caigan dentro de las competencias de cada una de las instituciones, considerándose que los documentos de carácter político, deliberaciones u opiniones de uso interno no entran en el supuesto de hecho objetivo de aplicación del Reglamento.

En lo que a contenido sustantivo se refiere, el Reglamento 1049/2001 refleja fielmente el espíritu recogido en el artículo 42 de la Carta de los Derechos Fundamentales y en el artículo 255 del TFUE al consagrar categóricamente la apertura y la transparencia como el objetivo prioritario en su artículo $1.1^{34}$. En otras palabras, la regla general es la apertura, y las excepciones, pocas y contadas, cuya aplicación debe justificarse debidamente, deben también interpretarse restrictivamente. Recogidas estrictamente en el artículo 4 del Reglamento, afectan al interés público (por lo que respecta a la seguridad pública $^{35}$, la defensa y los asuntos militares, las relaciones internacionales ${ }^{36}$ o la política

31 Dicho artículo reza como sigue.:«1. A fin de fomentar una buena gobernanza y de garantizar la participación de la sociedad civil, las instituciones, órganos y organismos de la Unión actuarán con el mayor respeto posible al principio de apertura. 2. Las sesiones del Parlamento Europeo serán públicas, así como las del Consejo en las que éste delibere y vote sobre un proyecto de acto legislativo. 3. Todo ciudadano de la Unión, así como toda persona física o jurídica que resida o tenga su domicilio social en un Estado miembro, tendrá derecho a acceder a los documentos de las instituciones, órganos y organismos de la Unión, cualquiera que sea su soporte, con arreglo a los principios y las condiciones que se establecerán de conformidad con el presente apartado. El Parlamento Europeo y Consejo, con arreglo al procedimiento legislativo ordinario, determinarán mediante reglamentos los principios generales y los límites, por motivos de interés público o privado, que regulan el ejercicio de este derecho de acceso a los documentos. Cada una de las instituciones, órganos u organismos garantizará la transparencia de sus trabajos y elaborará en su reglamento interno disposiciones específicas sobre el acceso a sus documentos, de conformidad con los reglamentos contemplados en el párrafo segundo. El Tribunal de Justicia de la Unión Europea, el Banco Central Europeo y el Banco Europeo de Inversiones sólo estarán sujetos al presente apartado cuando ejerzan funciones administrativas. El Parlamento Europeo y el Consejo garantizarán la publicidad de los documentos relativos a los procedimientos legislativos en las condiciones establecidas por los reglamentos contemplados en el párrafo segundo.»

32 Desde el Tratado de Lisboa las instituciones han pasado a ser siete, y no cinco como eran antes.

33 Artículo 1 Reglamento 1049/2001.

34 «Todo ciudadano de la Unión, así como toda persona física o jurídica que resida o tenga su domicilio social en un Estado miembro, tiene derecho a acceder a los documentos de las instituciones, con arreglo a los principios, condiciones y limites que se definen en el presente Reglamento.»

35 Esta excepción se refiere indirectamente a la política de Justicia, Libertad y Seguridad de la Unión Europea. El concepto de «seguridad pública» se refiere tanto a la seguridad interior de un Estado miembro como a su seguridad exterior, así como al suministro de productos esenciales y a los riesgos que de ello pueden surgir para la subsistencia del Estado. Resulta especialmente interesante la sentencia de 17 de junio de 1998, asunto T-174/95 Svenska Journalistförbundet contra Consejo.

36 En este caso, la transparencia debe ceder ante la seguridad nacional, sobre todo en casos en los que la seguridad internacional pueda quedar comprometida por la revelación de estrategias de política exterior europea. 
financiera, monetaria o económica de la Comunidad o de un Estado miembro) ${ }^{37}$, a la intimidad y la integridad de la person ${ }^{38}$ o a intereses comerciales, procedimientos judiciales $^{39}$ o actividades de investigación o de auditoría ${ }^{40}$. Estudiemos ahora la interpretación que la jurisprudencia ha hecho de estas excepciones y las consecuencias de la configuración que le ha dado al derecho de acceso a documentos en los últimos años y, más concretamente, en la sentencia Bavarian Lager.

\section{MARCO JURISPRUDENCIAL. LA JURISPRUDENCIA DEL TRIBUNAL DE JUSTICIA DE LA UNIÓN EUROPEA SOBRE EL ACCESO PÚBLICO A LOS DOCUMENTOS DE LAS INSTITUCIONES}

Como mencionábamos más arriba, la labor del Tribunal de Justicia de la Unión Europea a la hora de forjar el derecho de acceso público a documentos a partir del principio de transparencia mucho antes de que lo hiciera la legislación europea ha sido esencial. La entrada en vigor del Reglamento 1049/2001 proporcionó finalmente al Tribunal el marco jurídico que necesitaba, de modo que a partir de entonces se ha dedicado a perfilar delicadamente los límites de dicho derecho y, sobre todo, de sus excepciones.

Véanse, por todas, la sentencia recaída en el asunto T-204/99 Olli Mattila contra Consejo y Comisión y la sentencia del Tribunal de Justicia de 6 de diciembre de 2001, asunto C-353/99 Consejo de la Unión Europea contra Heidi Hautala. Sin embargo, no es aplicable dicha excepción cuando las instituciones «actúan como meras observadoras de la realidad internacional» (sentencia de 7 de febrero de 2002, asunto T-211/00 Aldo Kuijer contra Consejo de la Unión Europea).

37 Artículo 4.1 a) del Reglamento 1049/2001: «Las instituciones denegarán el acceso a un documento cuya divulgación suponga un perjuicio para la protección de: a) el interés público, por lo que respecta a — la seguridad pública, la defensa y los asuntos militares, - las relaciones internacionales, - la politica financiera, monetaria o económica de la Comunidad o de un Estado miembro.»

38 Artículo 4.1.b) del Reglamento 1049/2001: «Las instituciones denegarán el acceso a un documento cuya divulgación suponga un perjuicio para la protección de la intimidad y la integridad de la persona, en particular de conformidad con la legislación comunitaria sobre protección de los datos personales.»

39 Esta excepción se refiere tanto a procedimientos judiciales ante la jurisdicción europea como a procedimientos nacionales. En el primer caso, como se estableció en la sentencia Interporc contra Comisión (asunto T92/98), no es posible eludir la obligación de facilitar los documentos que hayan sido elaborados en el marco de un expediente pura y simplemente administrativo, incluso si la aportación de dichos documentos en un proceso puede perjudicar a la institución. En el segundo caso, la sentencia de 19 de marzo de 1998, asunto T-83/98 Gerard van der Wal contra Comisión y la sentencia de 11 de enero de 2000, asuntos acumulados C-174/98 P y C189/98 P Países Bajos y Gerard van der Wal contra Comisión sentaron que sólo cabe restringir el acceso a los documentos elaborados por la Comisión a petición de un Juez nacional cuando se trate de documentos elaborados sólo para un procedimiento concreto y particular, y sólo en la medida en la que no se limiten a reproducir otros que ya existían o a emitir una opinión de carácter general, independientemente del asunto pendiente ante un Tribunal nacional.

40 Artículo 4.2 del Reglamento 1049/2001: «Las instituciones denegarán el acceso a un documento cuya divulgación suponga un perjuicio para la protección de:- los intereses comerciales de una persona física o jurídica, incluida la propiedad intelectual, - los procedimientos judiciales y el asesoramiento jurídico, - el objetivo de las actividades de inspección, investigación y auditoría, salvo que su divulgación revista un interés público superior.» 
Son muy numerosas las sentencias recaídas en procedimientos relacionados con el derecho de acceso público a los documentos ${ }^{41}$. Sin embargo, la jurisprudencia del Tribunal de Justicia de la Unión Europea se ha producido casi siempre al hilo de la posibilidad que el artículo 8.1 del Reglamento 1049/2001 concede al reclamante ${ }^{42}$. Este artículo prevé el derecho de recurrir, en caso de una denegación total o parcial de la solicitud confirmatoria $^{43}$ hecha por el interesado, concediéndole dos opciones: o bien dirigirse judicialmente contra la institución en cuestión, o bien interponer una reclamación ante el Defensor del Pueblo Europeo ${ }^{44}$. La abundancia de casos presentados tanto ante el Tribunal de Justicia como ante dicho Defensor les ha permitido trazar claramente las líneas jurisprudenciales del principio de transparencia en lo referente al acceso público a documentos.

Como se señaló convenientemente en el caso Aldo Kuijer ${ }^{45}$, las facultades del Juez europeo se limitan a examinar, en su caso, los documentos solicitados, pudiendo ordenar que se le presenten para apreciar la forma en la que las instituciones examinaron las solicitudes de acceso que, en su día, denegaron ${ }^{46}$. En consecuencia, puede también anular las decisiones denegatorias si las estima ilegítimas, pero sin que esto signifique que puede dirigir

41 Siguiendo a GUICHOT (op. cit. pág. 297), debemos convenir que la mayoría de dichas sentencias incluyen nuevos elementos que han ayudado a configurar el derecho tal y como se entiende hoy. Las primeras eran, de hecho, estudios de Derecho comparado, especialmente las conclusiones de los Abogados Generales. Al respecto conviene citar la sentencia recaída en el asunto C-353/99 P. Consejo contra Heidi Hautala, en el que el Abogado General Tesauro establece un principio que posteriormente ha servido para configurar no sólo el derecho que nos ocupa sino también el alcance de la confidencialidad a escala europea: «No es cierto que todo es confidencial salvo lo que de modo expreso se declara accesible, sino exactamente lo contrario.»

42 En ciertos casos, las instituciones han objetado que no cabe recurrir contra la denegación de acceso a documentos que los demandantes hayan podido obtener por otros medios con el único propósito de someter a examen el buen funcionamiento del sistema. Sin embargo, el principio general se mantiene, y por ello vela el Juez europeo: no es necesario motivar la solicitud, ya que el objetivo de la normativa de acceso es traducir el principio que postula por un acceso de los ciudadanos a la información lo más amplio posible para reforzar el carácter democrático de las instituciones y la confianza del público en la Administración. Ver, al respecto, las sentencias del Tribunal General recaídas en los asuntos T-174/95 Svenska Journalistförbundet contra Consejo, o T124/96 Interporc contra Comisión.

$43 \mathrm{El}$ procedimiento de solicitud de acceso se articula en torno a un doble mecanismo: las solicitudes iniciales y las confirmatorias. La denegación en respuesta a una solicitud inicial permite al interesado redactar una confirmatoria, de mayor formalidad. La denegación de la solicitud confirmatoria puede ser recurrida ante el Tribunal General (antes denominado de Primera Instancia) o, alternativamente, al Defensor del Pueblo Europeo.

44 En efecto, el artículo 8.1 del Reglamento 1049/2001 establece que «Las solicitudes confirmatorias se tramitarán con prontitud. En el plazo de 15 días laborables a partir del registro de la solicitud, la institución o bien autorizará el acceso al documento solicitado y facilitará dicho acceso con arreglo al artículo 10 dentro de ese mismo plazo, o bien, mediante respuesta por escrito, expondrá los motivos para la denegación total o parcial. En caso de denegación total o parcial deberá informar al solicitante de los recursos de que dispone, a saber, el recurso judicial contra la institución y/o la reclamación ante el Defensor del Pueblo Europeo, con arreglo a las condiciones previstas en los artículos 230 y 195 del Tratado $C E$, respectivamente» No debemos perder de vista el hecho de que la legitimación activa para cada uno de estos dos recursos es distinta, dado que el recurso al Defensor del Pueblo Europeo está reservado a ciudadanos, residentes y sociedades con domicilio en la Comunidad, de acuerdo con el artículo 2.3 de su Estatuto.

45 Sentencia de 7 de febrero de 2002, asunto T-211/00, fundamento jurídico 62.

46 La misma sentencia señala que es ésta una facultad que no ha de ejercitar siempre, sino sólo cuando lo estime necesario. 
a las instituciones u agencias órdenes para proveer el acceso ${ }^{47}$. En palabras de Guichot, es aquí donde se reproduce el delicado equilibrio entre respeto del poder de apreciación de los órganos competentes para decidir y el control judicial característico del Derecho público, tensión que se agudiza en el caso de información de naturaleza sensible ${ }^{48}$.

La jurisprudencia del Tribunal de Justicia que interpreta y aplica el derecho de acceso a documentos no ha destacado por su estabilidad. Existen numerosísimas sentencias, como las recaídas en el asunto Suecia y Turco contra el Consejo ${ }^{49}$ en los que el Tribunal de Justicia decidió exactamente lo contrario a lo decidido por el Tribunal General (antes de Primera Instancia de la Unión Europea). Esta oscilación en las opiniones de las dos instancias jurisdiccionales de la Unión Europea da fe de la niebla que todavía invade el impreciso concepto de transparencia y de los conflictos y reticencias que la revelación de información suscita en las instituciones europeas. Sin embargo, esto no resta ni un ápice de la importancia que la jurisprudencia tiene en la configuración de este principio. Valga decir que en el asunto Suecia y Turco contra el Consejo el Tribunal de Justicia sentenció que el Reglamento 1049/2001 impone, en principio, una obligación a las instituciones europeas de revelar las opiniones emitidas por sus Servicios Jurídicos acerca de cualquier procedimiento legislativo en curso ${ }^{50}$. En el mismo sentido, en el asunto Suecia contra Comisión Europea el Tribunal de Justicia estableció que ningún Estado miembro puede simplemente solicitar de una institución de la Unión que no revele a terceros documentos proporcionados por dicho Estado, sino que éste está obligado a justificar dicha solicitud de confidencialidad con base en alguna de las excepciones del artículo 4 del Reglamento ${ }^{51}$. En todo caso, el hilo jurisprudencial trazado por el Tribunal de Justicia de la Unión Europea parece, hasta el momento, ser coherente en una cosa: toda limitación a un derecho que entronca con el principio democrático ha de interpretarse restrictivamente, a la luz del derecho a la información y del principio de proporcionalidad, de modo que no se frustre la aplicación del principio general de libre acceso.

En lo que se refiere a la aplicación de las excepciones, ya señaló el Tribunal en los asuntos Suecia contra Comisión y Suecia y Turco contra el Consejo que deben interpretarse y aplicarse siempre en su sentido más estricto ${ }^{52}$. Además, existen otros criterios para su aplicación que son de origen exclusivamente jurisprudencial: por ejemplo, la investigación que toda solicitud de acceso a documentos requiere debe ser específica, y el solo he-

47 En efecto, como se señala en las sentencias Hanne Norup Carlsen (T-610/97) y Karl L. Meyer contra Comisión (T-106/99), son las agencias e instituciones las que deben extraer las consecuencias necesarias del fallo, bien procediendo a una nueva denegación suficientemente motivada (que también podrá ser recurrida), bien facilitando el acceso.

48 GUICHOT, op. cit. pág. 306.

49 Casos C-39/05 P y C-52/05 P (unidos).

50 Sin embargo, el Tribunal se ha preocupado también de enfatizar en cada sentencia al hilo del Reglamento 1049/2001 que dicha obligación no se aplica a opiniones de los Servicios Jurídicos que no se refieran a un procedimiento legislativo.

$51 \mathrm{Al}$ respecto, el Defensor del Pueblo Europeo ha señalado que las instituciones deberán igualmente justificar su negativa a aportar sus propios documentos de la misma forma que lo deben hacer los Estados miembros, dado que no hay razón por la cual las instituciones deban gozar de prerrogativas a este respecto. Ambas posturas se enmarcan dentro de la misma tendencia doctrinal, cada vez más favorable a la transparencia.

52 Asunto C-64/05 P Suecia contra Comisión [2007] ECR I-11389, párrafo 66, y Suecia y Turco contra el Consejo, fundamento jurídico 36. 
cho de que un documento verse sobre alguno de los intereses protegidos por una excepción no justifica de por sí la aplicación de dicha excepción ${ }^{53}$. Más aún: el riesgo que existe de dañar a uno de los intereses protegidos debe ser razonablemente previsible, y no una mera hipótesis ${ }^{54}$. Como ya dijo el Tribunal de Primera Instancia en el asunto API y el Tribunal de Justicia confirmó en la sentencia Turco, la institución debe justificar de qué manera la revelación de los documentos perjudicaría, en concreto, el interés protegido. En conclusión, el examen que la institución debe hacer de cada solicitud con el fin de aplicar cualquiera de las excepciones debe llevarse a cabo de un modo específico, señalado por la jurisprudencia, de manera que cada decisión de rechazo (es decir, la aplicación de una excepción) esté suficiente y sólidamente motivada.

Además, el examen debe hacerse por separado respecto de cada uno de los documentos a los cuales se solicita acceder (es decir, no está justificado realizar un análisis de la solicitud en general, sino que hay que justificar, en su caso, la denegación de cada uno de los documentos), y debe verificarse igualmente si es posible el acceso parcial a cada uno de los documentos solicitados, debiéndose conceder en caso de que lo sea, de acuerdo con el artículo 4.6 del Reglamento. Las excepciones que se recogen en los apartados 1 a 3 del artículo 4 se refieren, al fin y al cabo, a "un documento" ${ }^{55}$, en singular, detalle que apoya que la investigación y el examen de cada uno de ellos individualmente fue la verdadera intención del legislador. Debemos recordar también que todos estos requisitos previos a la aplicación de una excepción del artículo 4 deben seguirse escrupulosamente con independencia del tema sobre el que versen los documentos a los cuales se quiere acceder o la institución en cuyo poder obren ${ }^{56}$.

Del análisis jurisprudencial se deduce que el criterio que utilizan tanto el Tribunal General como el Tribunal de Justicia para determinar si es posible aplicar las excepciones al acceso general a documentos en el caso concreto es, en suma, un criterio teleológico; es decir, un análisis individualizado del bien jurídico que dichas excepciones buscan, en último término, salvaguardar. Las sentencias recaídas en los asuntos Turco y Suecia v Consejo, API y MyTravel dan fe de que la jurisprudencia ha considerado oportuno primar en

53 Así se señaló repetidas veces en asuntos previos, como Verein für Konsumenteninformation contra Comisión [2005] ECR II-1121, los asuntos conjuntos T-391/03 y T-70/04 Franchet y Byk contra Comisión [2006] pág. II2023 y el más reciente T-237/08 Éditions Odile Jacob SAS contra Comisión.

54 Así se recoge en los asuntos Association de la presse internationale ASBL (API) contra Comisión y MyTravel Group contra Comisión.

55 Ver, por ejemplo, el párrafo 70 del asunto T-2/03 Verein für Konsumenteninformation contra Comisión [2005] ECR II-0000.

56 El Tribunal de Primera Instancia, hoy Tribunal General, ha reconocido, sin embargo, que el examen pormenorizado de cada solicitud respecto de cada documento puede no ser necesario en casos en los que, por circunstancias particulares, sea obvio que el acceso debe denegarse o, por el contrario, concederse. Éste es el caso, entre otros, de los documentos que entran enteramente y de lleno en una de las excepciones, o que están manifiestamente fuera de todas ellas, o, finalmente, que ya han sido objeto de un examen concreto e individual al hilo de otra solicitud, en circunstancias similares (Ver asunto T-237/05 Éditions Odile Jacob SAS, párrafo 47). Por otro lado, si bien el Tribunal General ya se ha pronunciado contra el examen de los documentos por categorías, señalando que la investigación debe ser individualizada, está aceptado que se aplique la misma justificación en el caso de documentos que pertenezcan a la misma categoría, lo que suele ser el caso cuando se trata de documentos que contienen el mismo tipo de información. El Tribunal deberá determinar, cuando se someta a su jurisdicción, si dicha excepción cubre clara y totalmente los documentos pertenecientes a la misma categoría (Éditions Odile Jacob SAS, párrafo 86). 
ciertos casos valores jurídicos distintos a la transparencia tras el debido análisis pormenorizado de los bienes jurídicos en juego, esgrimiendo argumentos más o menos sólidos. A lo largo de este análisis tendremos la oportunidad de valorar el giro realizado por el Tribunal de Justicia y de bosquejar las consecuencias que aquél puede tener para el derecho de acceso público en el futuro.

\section{BAVARIAN LAGER. UNA REINTERPRETACIÓN DE LAS EXCEPCIONES}

El interés de la sentencia Bavarian Lager a los efectos de este análisis reside en que se refiere a la excepción de protección de la intimidad de los particulares (artículo 4.1.b) del Reglamento 1049/2001), tema de rabiosa actualidad en los foros europeos. La protección de la intimidad y la integridad del individuo es un bien jurídico que ha preocupado siempre al Tribunal de Justicia de la Unión Europea, y su compatibilidad con el derecho fundamental de acceso a documentos ha sido recientemente examinada en la sentencia recaída en el asunto Borax ${ }^{57}$, que es una de las más emblemáticas, a la par que una de las más recientes del Tribunal General. Dicha sentencia ya se centró en las relaciones entre el acceso a documentos, la protección de la intimidad y la protección de datos.

Borax era una empresa productora de compuestos potencialmente peligrosos, productos que corrían el riesgo de ser incluidos en una «lista negra» por sus elevados niveles de toxicidad. Dicha empresa requirió a la Comisión que le facilitase las conversaciones grabadas con ocasión de una reunión de expertos sobre la toxicidad de los productos y las transcripciones de las mismas ${ }^{58}$. A su primera solicitud la Comisión contestó denegándole dicho acceso, puesto que consideraba que la revelación de las grabaciones expondría a los expertos a influencias externas y afectaría a su integridad y a su intimidad. En la solicitud confirmatoria, Borax cuestionó dicho argumento, dado que la Comisión no señaló en concreto qué influencias podrían afectarles ni cuál era la dimensión de dicho riesgo. Más aún: Borax afirmó que los expertos que toman parte en dichas conversaciones no pueden esperar que sus identidades se mantengan en el anonimato ni que sus argumentos sean confidenciales, puesto que han elegido voluntariamente participar en un proceso, al fin y al cabo, legislativo, puesto que la Comisión partirá de sus opiniones a la hora de elaborar dicha lista. La Comisión contestó a esto que el hecho de participar en un procedimiento de consultas no priva al individuo al derecho a su intimidad y a la protección de sus datos tal y como se recoge en el Reglamento 45/200159 y se confirma en el

57 Asunto T-121/05 Borax Europe Ltd contra Comisión, sentencia de 11 de marzo de 2009. Véase especialmente el fundamento jurídico 70.

58 Borax especificó en su solicitud confirmatoria que se daría por satisfecha con una versión «anonimizada» de las conversaciones.

59 Reglamento 45/2001/CE del Parlamento Europeo y del Consejo, de 18 de Diciembre de 2000, sobre la protección de los individuos en lo referido al procesamiento de sus datos personales por parte de las instituciones y órganos de la Unión y sobre la libre circulación de dichos datos, OJ L 8, 12 enero 2001, pág.1. De acuerdo con su artículo 1.1, el objetivo del Reglamento es la protección de los derechos y libertades fundamentales de las personas naturales, y en particular su derecho a la intimidad en lo que respecta al procesamiento de sus datos personales. 
artículo 4.1.b) del Reglamento 1049/2001. No existe, por tanto, excepción a la aplicación de las normas de protección de datos de carácter personal para los sujetos que lleven a cabo funciones directamente relacionadas con su profesión.

Habría sido muy interesante que el Tribunal General hubiera dedicado parte de su análisis a la participación en procesos decisorios de una institución y a las implicaciones que ésta acarrea para los individuos, pero desgraciadamente no lo hizo. Lo que hizo fue considerar que la Comisión había citado el artículo 4.1.b) del Reglamento $1049 / 2001$ sin argumentos específicos ${ }^{60}$ acerca del riesgo de perjudicar la privacidad e intimidad del individuo o acerca del posible incumplimiento de las normas recogidas en el Reglamento 45/2001. De acuerdo con lo que hemos visto más arriba, el Tribunal General está actuando de una manera coherente, exigiendo la justificación y la prueba del riesgo que podría, en su caso, sustentar la aplicación de la excepción al principio general de acceso. Sería, por tanto, de esperar que el Tribunal de Justicia siguiera el mismo razonamiento. Sin embargo, no fue así: en el recurso de casación, dicho Tribunal arguyó que existe un objetivo último adicional a la excepción que nos ocupa, objetivo que el Tribunal General pasó por alto: la protección de los datos personales del individuo.

El asunto Bavarian Lager puede considerarse la culminación hasta el momento del camino jurisprudencial que Borax inició en su día en el conflicto transparencia - intimidad. El supuesto de hecho que dio lugar a la sentencia Bavarian Lager, a grandes rasgos, fue el siguiente: en 1993, la Comisión justificó su negativa a conceder cierta información al solicitante en razones de protección de datos personales. El solicitante era un empresario británico que se quejó ante la Comisión de ciertas leyes británicas que, en la práctica, restringían la importación de cerveza por parte de su empresa, la Bavarian Lager Company. En 1996, mientras investigaba los hechos que habían dado lugar a la queja, la Comisión convocó a una reunión, entre otros, a algunos representantes de la industria cervecera británica, así como a algunos funcionarios relacionados con dicha industria. Al reclamante no se le permitió asistir a dicha reunión, por lo que pidió a la Comisión que le facilitase los nombres de las personas que sí habían asistido, a lo cual aquélla se negó esgrimiendo que las normas de protección de datos la obligaban a mantener a los asistentes en el anonimato a no ser que ellos mismos consintieran la revelación de sus nombres ${ }^{61}$.

Posteriormente, cuando entró en vigor el Reglamento 1049/2001, el propietario de Bavarian Lager Company pidió acceso público al documento que contenía la lista de los

60 Como dijimos más arriba, es jurisprudencia consolidada que el solo hecho de que un documento se refiera a alguno de los intereses protegidos por alguna de las excepciones no constituye argumento suficiente para la aplicación de dicha excepción. Dicha aplicación puede justificarse solamente si la institución ha evaluado previamente si conceder el acceso al documento solicitado podría perjudicar el interés protegido de una manera específica y real. Además, el riesgo de que un interés protegido pueda verse atacado deber ser razonablemente previsible y no puramente hipotético, como se recoge en el fundamento jurídico 43 de la sentencia Suecia y Turco contra el Consejo, ya vista.

61 En el momento de recibir la primera solicitud de información por parte de Bavarian Lager, el 4 de mayo de 1998, la Comisión intentó conseguir el consentimiento de los implicados para poder revelar sus nombres. De acuerdo con ésta, dicho procedimiento era el previsto por las normas de protección de datos que estaban vigentes entonces. 
nombres. De nuevo la Comisión se negó a facilitarle dicho acceso ${ }^{62}$, de modo que al solicitante no le quedó otra opción que recurrir dicha decisión ante el Tribunal General. Como detalle interesante hay que señalar que el Supervisor Europeo de Protección de Datos $^{63}$ compareció ante el Tribunal General para opinar, como ya lo hicieron tanto el Defensor del Pueblo Europeo como el Parlamento Europeo ${ }^{64}$, que la Comisión había tergiversado el significado de la normativa de protección de datos y en este caso no la estaba aplicando correctamente.

Por fin, en octubre de 2007 el Tribunal General falló que la Comisión debía revelar los nombres al solicitante. Como ya vimos en la sentencia del asunto Borax, el Tribunal consideró que no se había probado suficientemente que la protección de la intimidad y de la integridad del individuo se vería disminuida por el hecho de revelar su asistencia a una reunión ${ }^{65}$. La Comisión, como es su deber, se plegó a lo que le exigía el Tribunal Gene-

62 En efecto, en 2004 la Comisión comunicó a Bavarian Lager Company que, dado que ya habían entrado en vigor tanto el Reglamento 1049/2001 como el 45/2001, la solicitud de información que la empresa hacía debía tramitarse conforme al procedimiento establecido en dichos Reglamentos, y en especial el artículo 8(b) del Reglamento 45/2001, que dice lo siguiente:

«Los datos personales sólo se transmitirán a destinatarios sujetos al Derecho nacional adoptado para la aplicación de la Directiva 95/46/CE, cuando: (...) b) el destinatario demuestre la necesidad de que se le transmitan los datos y no existan motivos para suponer que ello pudiera perjudicar los intereses legítimos del interesado.»

También justificó la Comisión su negativa en el derecho que tenía cada uno de los asistentes a negarse a que sus datos personales sean transmitidos a terceros o procesados, datos entre los cuales debe sin lugar a dudas figurar el nombre. Sin embargo, Bavarian Lager no se dio por satisfecha y repitió sus solicitudes, esgrimiendo diferentes argumentos, en varias ocasiones. En 2004 la Comisión le remitió un documento que contenía las actas de la reunión de 1996, pero en dicho documento cinco de los nombres habían sido borrados. De ellos, tres no habían podido ser localizados a efectos de preguntarles si consentían la publicación de sus nombres, mientras que los dos restantes se habían opuesto explícitamente a dicha publicación.

63 Aunque no es el objeto de este trabajo, es necesario dedicar, siquiera una nota al pie, al Supervisor Europeo de Protección de Datos, que gana cada vez más importancia con su papel de regulador del uso que de los datos personales hacen las instituciones europeas, así como promotor de iniciativas de protección de dichos datos.

64 Es especialmente interesante la resolución del Parlamento Europeo sobre el informe especial redactado siguiendo la recomendación del Defensor del Pueblo a la Comisión, en la cual no podemos detenernos.

65 Merece la pena hacer una referencia, siquiera breve, a los argumentos esgrimidos por el Tribunal para desmontar la defensa de la Comisión, por cuanto constituyen un excelente ejemplo de técnica y visión jurídicas. En concreto, el Tribunal señaló: En lo que respecta a la obligación del solicitante de probar la necesidad que tiene de obtener los datos personales (es decir, los nombres) que requiere de acuerdo con el artículo 8 b) del Reglamento 45/2001, dicha obligación debe ser interpretada en consonancia con la que deriva del artículo 6.1 del Reglamento 1049/2001. De acuerdo con este último, la persona que solicite el acceso público a un documento no está obligada a probar interés alguno en los documentos que solicita. Además, recalca, habida cuenta de lo dispuesto por el artículo 4.1.b) de este último Reglamento, en todo caso se denegará el acceso en el caso de que la revelación de algún dato pueda perjudicar la intimidad o la integridad de una persona. En conclusión, debe considerarse que toda solicitud que no caiga dentro de la excepción del artículo 4.1.b) se realiza con un interés legítimo entendido según el artículo 6.1 del Reglamento 45/2001. En lo que respecta al derecho de la persona a negarse a que sus datos sean facilitados a terceros (artículo 18 del Reglamento 45/2001), el Tribunal se fijó en la excepción que recoge el mismo artículo: los casos que caen dentro del artículo 5.b) del mismo. El artículo 5.b) señala que el tratamiento de datos personales deberá realizarse sólo si «es necesario para el cumplimiento de una obligación jurídica a la que esté sujeto el responsable del tratamiento». El responsable del tratamiento es la Comisión, que está sujeta a facilitar el acceso público a los documentos que obran en su poder de acuerdo con el Reglamento 1049/2001, de modo que la posibilidad de oponerse a dicho tratamiento está subyugada a las obligaciones de la Comisión y ésta debía facilitar tales datos. En otras pa- 
ral, pero recurrió en casación al Tribunal de Justicia ${ }^{66}$ arguyendo que siempre que existan datos personales de por medio, las normas de transparencia (esencialmente el Reglamento 1049/2001) dejan paso a las de protección de datos, excluyéndose completamente la aplicación de las primeras. Añadió también que la interpretación sistemática que el Tribunal General quería hacer de la excepción contenida en el artículo 4.1.b) del Reglamento 1049/2001 no contemplaba lo recogido en el segundo inciso de dicho punto, es decir, que las instituciones pueden denegar el acceso a un documento siempre que la revelación de los datos que contenga pueda perjudicar la protección de la intimidad y la integridad del individuo «en particular de conformidad con la legislación comunitaria sobre protección de los datos personales».

Apoyada por el Consejo y por el Reino Unido, la Comisión señaló también en su apelación que el Tribunal General, fallando como lo había hecho, había convertido en virtualmente inaplicables ciertos preceptos del Reglamento 45/2001. Específicamente, la Comisión se refirió a la obligación de presentar un interés legítimo a la hora de solicitar los datos personales de un tercero. Dicho precepto, contenido, como ya hemos visto, en el artículo 8 b) del Reglamento 45/2001, es uno de los preceptos clave para la protección de los datos de carácter personal, de modo que obviarlo o subyugarlo a las disposiciones del Reglamento 1049/2001 es atacar de lleno la línea de flotación de la protección de la intimidad. Además, al asegurar que las obligaciones legales de las instituciones, tal y como se recogen en el artículo 5 b) del Reglamento $45 / 2001$, priman sobre la protección de los datos personales de los particulares, el Tribunal General estaba en realidad privando de todo sentido al artículo 18 a) de dicho Reglamento, dado que impide a los particulares pronunciarse sobre el uso de sus datos en el caso de que la institución europea que los posea esté obligada a proporcionarlos a un tercero.

El Tribunal de Justicia dio la razón a la Comisión en el punto referido a la omisión en la interpretación del segundo inciso del artículo 4.1.b) del Reglamento 1049/2001, el cual, en sus palabras, es un precepto indivisible y requiere que cualquier ataque a la intimidad o a la integridad del individuo se examine y evalúe de acuerdo con la legislación europea vigente, y en particular con el Reglamento 45/2001. Considera el Tribunal que

\footnotetext{
labras, en este caso concreto la pugna entre dos bienes jurídicos (la intimidad y la transparencia) se resuelve a favor de ésta última. Sin embargo, como recordaremos, el artículo 4.1.b) del Reglamento 1049/2001 contenía, a su vez, una excepción a dicha obligación legal. Dicho artículo establece que «Las instituciones denegarán el acceso a un documento cuya divulgación suponga un perjuicio para la protección de (...) la intimidad y la integridad de la persona, en particular de conformidad con la legislación comunitaria sobre protección de los datos personales.» Por ello, el Tribunal se vio obligado a entrar a ponderar el efecto que la revelación de los datos en concreto podía tener en los individuos implicados, concluyendo que dicha excepción debía interpretarse siempre restrictivamente, aplicándose sólo respecto de datos personales que verdaderamente pudieran potencialmente afectar a la intimidad o a la integridad de la persona, datos entre los cuales no debe encontrarse el nombre propio. El artículo 8 del Convenio Europeo de los Derechos Humanos, así como la jurisprudencia que lo ha interpretado, apoyan esta postura. En conclusión, el Tribunal General consideró que la Comisión había interpretado erróneamente dichos artículos exigiendo que Bavarian Lager proporcionase pruebas de un interés legítimo en obtener los nombres de las cinco personas que asistieron a la reunión y que posteriormente, activa o pasivamente, no autorizaron la difusión de sus nombres.
}

66 Por una cuestión de derecho, de acuerdo con el artículo 256 TFUE. 
el artículo 4.1.b) establece un sistema «reforzado» y específico de protección de un particular cuyos datos personales podrían, en ciertos casos, publicarse, de modo que, cuando una solicitud de acuerdo con el Reglamento 1049/2001 persiga obtener acceso a documentos que incluyan datos personales, los preceptos del Reglamento 45/2001 deben aplicarse en su integridad, incluidos los artículos 8 y $18^{67}$. Dichos artículos constituyen dos pilares esenciales de la protección vertebrada en el Reglamento 45/2001. Por tanto, termina el Tribunal de Justicia, la interpretación sistemática que de ellos hace el Tribunal General resulta restrictiva en exceso y no se corresponde con el equilibrio que la legislación europea buscaba entre los dos Reglamentos.

Al fin y al cabo, reconoce el Tribunal de Justicia, Bavarian Lager tuvo finalmente acceso a toda la información relevante de la reunión habida el 11 de octubre de 1996, incluidas las opiniones que durante la misma vertieron los que asistieron. La Comisión actuó correctamente, en opinión del Tribunal, cuando verificó si los asistentes habían dado su consentimiento a la divulgación de sus nombres y cuando intentó contactar con ellos con el fin de obtener dicho consentimiento. Además, sigue el Tribunal de Justicia, dado que Bavarian Lager no había presentado ninguna justificación expresa ni había esgrimido ningún interés legítimo en su solicitud de acceso, y ni siquiera había argumentado nada para probar que necesitaba que se le procurasen dichos datos, la Comisión carecía de datos suficientes para poder ponderar los intereses en juego; en otras palabras, dada la falta del porqué de la solicitud de Bavarian Lager, la Comisión había hecho prevalecer la intimidad y la protección de los datos personales de los asistentes a la reunión. Al no saber el uso que se iba a dar a esos datos, ni siquiera podía determinar si el concederlos perjudicaría a los asistentes o si, por el contrario, no les causaría daño moral alguno. Como consecuencia, el Tribunal de Justicia, dando por completo la vuelta al razonamiento y a la sentencia del Tribunal General, concluyó que la Comisión había actuado correctamente y que, tras la interpretación que éste hace, no hay lugar a apreciar fallo alguno por parte de la Comisión.

Como ya hemos visto en distintas ocasiones, la ponderación de los intereses que existen en conflictos entre la transparencia y la protección de los datos de carácter personal requiere un delicado análisis del que surja el equilibrio más perfecto posible. Al fin y al cabo, la protección y la promoción tanto de la transparencia como del respeto a la intimidad del individuo son bienes jurídicos que la Unión Europea pone gran ímpetu en preservar, sobre todo en los últimos años. Tal vez sea conveniente recordar que tanto el derecho de acceso a documentos como el de respeto a la vida privada y familiar y el de

67 Reproducimos aquí el contenido de dichos artículos: Artículo 8: «Sin perjuicio de lo dispuesto en los artículos 4, 5, 6 y 10, los datos personales sólo se transmitirán a destinatarios sujetos al Derecho nacional adoptado para la aplicación de la Directiva 95/46/CE, cuando: a) el destinatario demuestre que los datos son necesarios para el cumplimiento de una misión de interés público o son inberentes al ejercicio del poder público, o b) el destinatario demuestre la necesidad de que se le transmitan los datos y no existan motivos para suponer que ello pudiera perjudicar los intereses legítimos del interesado.» Artículo 18: «El interesado tendrá derecho a:a) oponerse en cualquier momento, por razones imperiosas y legítimas propias de su situación particular, a que los datos que le conciernan sean objeto de tratamiento, salvo en los casos contemplados en las letras b), c) y d) del artículo 5. En caso de oposición justificada, el tratamiento en cuestión no podrá referirse ya a esos datos.b) ser informado antes de que los datos personales se comuniquen por primera vez a terceros o se utilicen por cuenta de terceros a efectos de prospección, y a que se le ofrezca expresamente el derecho a oponerse, sin gastos, a dich a comunicación o utilización.» 
protección de los datos personales son derechos fundamentales ${ }^{68}$. Como acabamos de ver, el Tribunal de Justicia, contradiciendo al Tribunal General, afirmó en la sentencia $B a$ varian Lager que el Reglamento 45/2001 es aplicable en su totalidad a las solicitudes de acceso a documentos realizadas de acuerdo con el Reglamento 1049/2001.

Intentemos contextualizar ahora el significado de esta resolución. Es ya jurisprudencia consolidada del Tribunal de Justicia la doctrina de que, en el caso de que sea necesario interpretar una disposición de Derecho derivado, debe siempre darse prioridad en lo posible a la versión que la haga más coherente con los Tratados y con los principios generales del Derecho europeo ${ }^{69}$. También es un principio general del Derecho europeo el de transparencia y apertura en las actuaciones de las instituciones de la Unión ${ }^{70}$. Volviendo ahora a las líneas que al principio de este trabajo escribimos sobre la transparencia, y la importancia que ésta tiene para la legitimidad de la Unión y de sus instituciones a ojos de los ciudadanos, no podemos dejar de sorprendernos de que la transparencia brille por su ausencia en el alegato del Tribunal de Justicia, que da la razón a la Comisión y opta por proteger la intimidad de los asistentes a la reunión sin ni siquiera mencionar el principio de transparencia. Parecería que el ejercicio de ponderación del Tribunal, que en teoría debía también basarse en el principio de proporcionalidad, ha borrado directamente uno de los dos platillos de la balanza y ha contribuido con su sentencia a que ésta se incline estrepitosamente por uno de los dos extremos.

Más aún: también es jurisprudencia consolidada del Tribunal de Justicia que la interpretación de cualquier precepto de Derecho europeo debe trascender la literalidad de la redacción para enfocar el contexto de la norma y el resto de preceptos que se relacionan con la misma; esto es, la conocida interpretación sistemática ${ }^{71}$. Es cierto que el artículo 4.1.b) del Reglamento 1049/2001, como dice el Tribunal de Justicia, es un precepto indisoluble e indivisible, y que la interpretación del mismo debe también incluir el inciso final; sin embargo, llama la atención el hecho de que el Tribunal de Justicia no haya tenido en cuenta que la excepción de dicho artículo ya menciona la aplicación del Reglamento 45/2001, al que el Tribunal quiere oponerla, cuando dice «[..] de conformidad con la legislación comunitaria sobre protección de los datos personales». En otras palabras, el Tribunal de Justicia parece pasar por alto el hecho de que la protección de los datos personales ya está incluida en el artículo que permite la excepción al principio general de acceso público a los documentos, y resulta, por tanto, ciertamente curioso que el Tribunal haya primado sin reservas la aplicación del Reglamento 45/2001, sin entrar si-

68 En efecto, la Carta de los Derechos Fundamentales de la Unión Europea reza: Artículo 42: «Todo ciudadano de la Unión y toda persona física o jurídica que resida o tenga su domicilio social en un Estado miembro tiene derecho a acceder a los documentos de las instituciones, órganos y organismos de la Unión, cualquiera que sea su soporte.»; Artículo 7: «Toda persona tiene derecho al respeto de su vida privada y familiar, de su domicilio y de sus comunicaciones.»; Artículo 8: «1. Toda persona tiene derecho a la protección de los datos de carácter personal que le conciernan. 2. Estos datos se tratarán de modo leal, para fines concretos y sobre la base del consentimiento de la persona afectada o en virtud de otro fundamento legítimo previsto por la ley. Toda persona tiene derecho a acceder a los datos recogidos que le conciernan y a obtener su rectificación. 3. El respeto de estas normas estará sujeto al control de una autoridad independiente.»

69 Así se recoge, por ejemplo, en el asunto C-314/89 Rauh, en el fundamento jurídico 17.

70 Así aparece en el artículo 15 del TFUE, que reprodujimos más arriba.

71 Recogido también en la jurisprudencia; por ejemplo, en la sentencia del asunto E. Merck contra Hauptzollamt Hamburg-Jonas de 1983 (fundamento jurídico 12). 
quiera a ponderar su relación con la transparencia, de acuerdo a lo que exige el citado artículo.

Una aplicación tan radical del Reglamento 45/2001 choca incluso con el principio básico que intenta proteger dicha norma. Parémonos un momento a analizar los bienes jurídicos en juego. Es cierto que el nombre propio es una de las manifestaciones más puras de la individualidad y de la personalidad de un ser humano y que constituye sin duda el núcleo duro de sus datos personales, como ha recogido en diversas ocasiones la jurisprudencia $^{72}$. No obstante, esto no significa que el nombre propio pertenezca a la intimidad de una persona, sobre todo cuando lo que está en juego es la transparencia de la actuación de las instituciones europeas. El matiz, que no es baladí, puede pasar fácilmente desapercibido. Para intentar aclararlo, volvamos un momento a la norma. El artículo 1 del Reglamento 45/2001 establece en su primer apartado que: «(l)as instituciones y los organismos creados por los Tratados constitutivos de las Comunidades Europeas o en virtud de dichos Tratados, en lo sucesivo denominados «instituciones y organismos comunitarios», garantizarán, de conformidad con el presente Reglamento, la protección de los derechos y las libertades fundamentales de las personas físicas, y en particular su derecho a la intimidad, en lo que respecta al tratamiento de los datos personales (...).»

En otras palabras, el Legislador europeo parece no albergar dudas sobre ello: el sentido último del Reglamento 45/2001 es la «protección de los derechos y las libertades fundamentales de las personas físicas», entre los cuales, recordemos, se encuentra también el acceso a documentos, «y en particular su derecho a la intimidad,» que es uno de estos derechos, «en lo que respecta al tratamiento de los datos personales».

Dos conclusiones palmarias pueden extraerse de la dicción de este artículo. La primera de ellas es que no todos los datos personales pueden considerarse como datos íntimos, y no todo tratamiento de los datos personales perjudica a la intimidad de la persona. El Reglamento 45/2001 es claro al respecto: existe la posibilidad de que determinados tratamientos de los datos personales ataquen a la intimidad de la persona, y son dichos tratamientos, y no otros, los que el Reglamento pretende erradicar. Más aún: realizando un análisis teleológico como los que hace el Tribunal de Justicia, el fin de la norma es la protección de los «derechos fundamentales». ¿Qué derecho fundamental, podemos preguntarnos, se protege por medio de abrir la puerta a reuniones «anónimas» en el contexto de la Administración Pública europea? Al fin y al cabo, esto es lo que el Tribunal está permitiendo al aplicar tan tajantemente el Reglamento 45/2001: la convocatoria de reuniones con partes interesadas (muy posiblemente colectivos conocidos como lobbies) a puerta inevitablemente cerrada y sin posibilidad de conocer la identidad de los asistentes. Hemos de añadir, a este respecto, que asumimos que los asistentes a tales reuniones lo hacen a título de profesionales del sector público o privado y no a título privado en tanto que ciudadanos individuales desligados de su actividad profesional, puesto que en este último supuesto la protección de los datos personales de un particular tendría algún sentido, pero encerraría un núcleo envenenado. En otras palabras, damos por hecho que los representantes de asociaciones, gobiernos y grupos de interés actúan en cuanto tales, defendiendo los intereses del colectivo al que representan, y no como par-

72 Ver, por ejemplo, la sentencia de 2 de octubre de 2003, asunto C-148/02 García Avello. 
ticulares en defensa de sus intereses privados. En este caso, no puede argüirse sólidamente que su nombre pertenezca a la esfera de su intimidad, sino que, bien al contrario, debe considerarse como el del portavoz de un interés colectivo que debe ser público para cualquier ciudadano. De ser otro el caso, la sentencia del Tribunal de Justicia en el asunto $B a$ varian Lager sería la condena a muerte de la transparencia de cualquier proceso de toma de decisiones en la Unión Europea.

La segunda conclusión, nacida directamente de la primera, es descorazonadora: al invertir el razonamiento que hizo el Tribunal General, el Tribunal de Justicia manifiesta un interés muy escaso en profundizar en la excepción del artículo 4.1.b) y en la proporcionalidad que requiere el equilibrio entre la protección de los datos personales y la transparencia en la actuación de las instituciones. El Tribunal no parece conceder importancia al hecho de que el mismo artículo 4.1.b) del Reglamento 1049/2001 contemple claramente la protección de la intimidad y la integridad de la persona con el fin de reforzarla, permitiendo denegar el acceso a los documentos que puedan perjudicarla cuando contengan datos personales. Este artículo llama a la interpretación, a la ponderación, a la observación y al detalle en el caso concreto, tarea que el Tribunal de Justicia, al contrario que el Tribunal General, decidió en esta sentencia no abordar, destruyendo, nunca mejor dicho, a golpe de sentencia lo que podría haber sido una excelente oportunidad para profundizar en el conflicto entre intimidad y transparencia.

Por otro lado, y en otro orden de cosas, el Tribunal de Justicia, al apoyar la visión de la Comisión de que Bavarian Lager no había justificado el interés que tenía en conseguir los datos solicitados, parece estar también abriendo camino a la necesidad de justificación del interés del solicitante, algo que va frontalmente en contra de la legislación que hemos analizado en el apartado correspondiente. El hecho de no haber esgrimido los argumentos por los cuales creía tener acceso a los documentos le cuesta a Bavarian Lager la desestimación de sus argumentos y lanza un jarro de agua fría al Tribunal General que se nos antoja injusto, por cuanto en ningún momento el Reglamento 1049/2001 exige la prueba de dicho interés. La repercusión de este argumento puede ser enorme, por cuanto por vía de sentencia el Tribunal de Justicia está dando al traste con la razón de ser del acceso público a documentos y de la transparencia, que es que cualquier ciudadano, por el mero hecho de serlo, tiene derecho a que se abran ante él los archivos de las instituciones y órganos europeos sin tener que justificar qué le mueve a solicitar el acceso a los mismos.

\section{CONCLUSIONES}

Las consecuencias de esta sentencia pueden ser desastrosas para el principio de transparencia. De acuerdo con los Tratados, las sentencias del Tribunal de Justicia de la Unión Europea tienen fuerza ejecutiva ${ }^{73}$, de modo que a las instituciones, entre otros, se les obliga a obedecerlas y a ajustar su actuación a lo que en ellas se ha plasmado como jurisprudencia. A partir de la sentencia Bavarian Lager, en la pugna entre transparencia y protección de datos personales (que no protección de la intimidad, como ya hemos visto), gana

73 Artículo 280 TFUE.

UNED. Teoría y Realidad Constitucional, núm. 28, 2011, pp. 383-406. 
siempre la segunda: la obligación de conceder el acceso a los documentos públicos se subyuga a la protección de los datos personales de los intervinientes en un acto concreto, sin que haya lugar a la ponderación que la excepción del artículo 4.1.b) sugiere. Es cierto que Bavarian Lager no presentó ningún interés ni argumento que le favoreciera a la hora de inclinar la balanza a su favor, de modo que ni la Comisión ni el Tribunal pudieron valorar el peso de dichos argumentos contra la «resonancia jurídica» de la protección de datos de acuerdo con el artículo 8.b) del Reglamento 45/2001. Sin embargo, en puridad Bavarian Lager no estaba obligado a aportarlos. Más aún: volviendo contra el Tribunal su propio argumento, también carecía la Comisión (como también el Tribunal General y el Tribunal de Justicia) de argumentos a favor de los asistentes, puesto que éstos tampoco esgrimieron en qué medida o cómo podría el hecho de haberse dado a conocer sus nombres atentar a su intimidad o perjudicar su integridad, sobre todo, como ya hemos visto, teniendo en cuenta que asistían en concepto de profesionales cuyo cargo ostentan públicamente.

Aunque en esta ocasión lo ha evitado, parece necesario que en algún momento el Tribunal de Justicia entre con más detalle en la espinosa cuestión de la delimitación de qué datos personales constituyen la intimidad y la integridad de la persona a los efectos del derecho de acceso a documentos. Entretanto, las instituciones y autoridades europeas, así como los ciudadanos interesados, deberán cambiar su forma de actuar. Las primeras deberán adelantarse a las posibles solicitudes de acceso a documentos que puedan producirse. No hay que olvidar que el TFUE les obliga a actuar «con el mayor respeto posible al principio de apertura ${ }^{74} »$ sin descuidar por ello la protección de la intimidad de los particulares. A la luz de la reciente jurisprudencia que parece forjar el Tribunal de Justicia, parecería razonable que las instituciones se planteasen recabar el consentimiento de los participantes en su proceso decisorio de antemano, o, mejor aún, informarles de que el mero hecho de asistir a reuniones como la de este caso o participar en actividades dentro de la esfera de poder público de la Comisión comporta inmediatamente la aceptación a la posible publicación de sus nombres ${ }^{75}$.

A la luz de este análisis, parece que el principio de transparencia y apertura que el Reglamento 1049/2001 pretende consagrar y defender puede verse seriamente limitado por la interpretación jurisprudencial que de las excepciones se haga. De hecho, la sentencia Bavarian Lager nos muestra a un Tribunal de Justicia condescendiente con la Comisión y reticente a ampliar la aplicación del principio transparencia, favoreciendo el otro interés jurídico en juego (en consonancia con las reticencias que la revisión del Reglamento 1049/2001 suscita a día de hoy en las instituciones). En segundo lugar, es también reseñable el hecho de que el Tribunal General haya intentado por todos los medios a su alcance primar la transparencia y que el Tribunal de Justicia haya anulado dichos intentos. El Juez europeo que otrora prácticamente creó de la nada, puesto que no había previsión legislativa al respecto, el derecho de acceso basándose en el principio de trans-

74 Artículo 15.1 TFUE. Este inciso no tiene antecedentes en la redacción anterior de los Tratados. Representa un cambio radical que obliga a las instituciones a asegurar de manera proactiva la apertura de sus actividades.

75 Esta idea es coherente con el registro de grupos de interés que ha puesto en marcha la Comisión Europea. Aunque no podemos ocuparnos de él aquí, es muy recomendable visitar la página web para tener una idea, siquiera sucinta, de la enorme importancia que esta iniciativa tiene en el marco de la transparencia y del control democrático de las actividades de la Unión. 
parencia y en el principio democrático que rige la Unión da hoy la espalda al ciudadano, limitándole en ciertos casos la legitimación activa, esgrimiendo bienes jurídicos de dudosa solvencia como justificaciones para no publicar la información o creando procedimientos específicos no contemplados por la norma que, en teoría, debe aplicarse a cualquier solicitud de acceso. El contraste con la visión pro-transparencia del Tribunal General hace más evidente si cabe la incongruencia de los razonamientos y demuestra la debilidad de una jurisprudencia oscilante que todavía puede ser reorientada, idealmente en pos de una mayor apertura y de un ejercicio más sencillo del derecho fundamental, no lo olvidemos, de acceso público a los documentos.

$$
* * *
$$

TITLE: The Role of Case-Law in the shaping of access to documents in the EU

ABSTRACT: Regulation 1049/2001 establishes and shapes the right of access to documents in the European Union. This right is limited by a series of colliding principles and rights, such as privacy of personal data, 'ordre public' or commercial interests. The European Court of Justice, through rulings by each one of its two Courts (the General Court and the European Court), has shaped and generally extended the scope of Regulation 1049/2001, increasing transparency in the institutions. However, there is no clear case-law trend as regards access to documents, since rulings often contradict each other and precedents are of relatively little value. Recent rulings, such as those given to the Borax and Bavarian Lager cases, seem to restrict public access to documents in the institutions by placing access to documents under other values such as privacy and data protection. This trend seems again to contradict what the Lisbon Treaty and the European Charter of Fundamental Rights have just introduced: a bigher consideration of access to documents and a clear commitment with institutional transparency. This paper aims at giving a clear overview of the evolution and state of play of the right of public access to documents in the European legislation and case law. By analyzing the latest legal and jurisprudential developments, it can be concluded that law and case law do not seem to go hand in hand yet and seem to contradict each other. Immediate and further developments should be watched with a careful eye, as these will shape the post-Lisbon concept of access to documents. Consequently, essential principles such as transparency and data protection might undergo as well important changes.

RESUMEN: El Reglamento 1049/2001 consagra y configure el derecho de acceso público a documentos en la Unión Europea. Este derecho está limitado por ciertos bienes jurídicos en conflicto, como la privacidad de los datos personales, el orden público o los intereses comerciales. El Tribunal de Justicia de la Unión Europea, a través de las sentencias emanadas de sus dos instancias, ha pulido y en general extendido el campo de aplicación del Reglamento 1049/2001, aumentando la transparencia en las instituciones. Sin embargo, no hay una línea jurisprudencial clara al respecto, dado que las sentencias a menudo se contradicen entre sí y los precedentes jurisprudenciales parecen tener escaso valor en los asuntos posteriores. Algunas sentencias recientes, como las recaidas en los asuntos Borax $y$ Bavarian Lager, parecen por el contrario restringir el derecho de acceso a documentos, dado que hacen prevalecer otros bienes jurídicos como la privacidad o la protección de datos. Esta última tendencia parece contradecir al Tratado de Lisboa y a la Carta Europea de Derechos Fundamentales, puesto que éstos han introducido una mayor consideración al derecho de acceso a documentos con el fin de aumentar la transparencia institucional. Este artículo busca procurar una panorámica general de la evolución y el estado actual del derecho de acceso público a los documentos tanto en la legislación como en la jurisprudencia europeas. Del análisis tanto de las novedades legislativas y jurisprudenciales al respecto se deduce que ambas no parecen ir a la par, sino que llegan incluso a contradecirse. El desarrollo futuro tanto de la ley como de la jurisprudencia deberán ser objeto de estudio detallado, dado que serán determinantes en la configuración del derecho de acceso a documentos tras el Tratado de Lisboa. Como consecuencia de esto, puede que ciertos principios también fundamentales, como la transparencia o la protección de datos, sufran importantes cambios en un futuro inmediato.

KeY Words: Access to documents. Transparency. Fundamental Rights. Case law.

Palabras Clave: Acceso a documentos. Transparencia. Derechos fundamentales. Jurisprudencia.

FECHA DE RECEPCIÓN: 15.11.2010 FeCHA DE ACEPTACIÓN: 4.05.2011

UNED. Teoría y Realidad Constitucional, núm. 28, 2011, pp. 383-406. 